\title{
ANALYSIS OF A HYBRID CASCADED LATENTISENSIBLE STORAGE SYSTEM FOR PARABOLIC-TROUGH SOLAR THERMAL PLANTS
}

\author{
M.D. Muhammed ${ }^{1,2^{\star}}$, O. Badr ${ }^{1}$
}

\begin{abstract}
The molten-salt two-tank system is the state-of-the-art thermal storage technology employed in the more mature parabolic-trough solar thermal power generation using synthetic oil as the heat-transfer fluid (HTF). This storage technology requires high storage-material inventory, making it very expensive. The use of latent-heat storage (LHS) system offers smaller storage size and material inventory. However, such a storage system faces two challenges: there are limited number of commercially-available phase-change materials (PCMs) are suitable in the operating temperature range; and these materials have very low thermal conductivities. The use of finned tubes, nevertheless, can overcome the later shortcoming. In this study, the analysis of a hybrid storage system, consisting of a three cascaded finned-tube LHS stages and a sensible concrete tube register stage, was carried out through modelling and simulation. A procedure for the design of the finned-tube cascaded LHS stages was developed. For a typical $50 \mathrm{MW}$ parabolic-trough solar thermal power plant, the dimensions of a storage system with 6 hours of operation at full load were obtained. The three-stage cascaded LHS sub-system provides $45.5 \%$ of the total storage capacity of the entire system and has a volumetric specific capacity of $54 \%$ greater than that of the two-tank system. The volumetric specific capacity of the entire storage system is $9.3 \%$ greater than that of the two-tank system.
\end{abstract}

Keywords: Latent Heat Storage, Sensible Storage, Parabolic-trough Solar Thermal Power Generation Dymola, Modelling and Simulation

\section{INTRODUCTION}

The parabolic-trough solar thermal power generation technology is the most mature concentrated solar power technology. Three HTFs can be employed in the solar field: Thermal oil [1], molten salt [2,3] and water/steam [4-6]. The operation and maintenance experience gained in the successful commercial operation of the 354 MW, Solar Electricity Generating Stations (SEGS) plants in California, USA for over two decades [1] and their cost effectiveness in the medium-scale capacities (i.e. $<200 \mathrm{MW}$ ) led to the deployment of many commercial plants world-wide. Currently, there is $2.68 \mathrm{GW}$ of capacity in operation with thermal oil as the HTF and another 1.4 GW under construction around the world [7, 8]. Most of these plants are equipped with molten-salt two-tank storage systems, which have high investment cost due to the expensive molten-salt/HTF heat exchangers and the large storage material inventory. They also have high energy requirements due to the need to prevent the storage material (i.e. molten-salt) from solidifying.

The utilization of the energy absorbed or released when a material changes phase (i.e. latent heat) offers higher storage density and small operational temperature difference, thus have the potential of resulting in a more compact and efficient latent-heat storage system compared with the traditional sensible-heat molten-salt system. This can lead to a reduction in the levelised electricity cost (LEC) for the solar plant.

The operating temperature of the synthetic oil in parabolic-trough solar power plants ranges between 2910C and 393oC. Therefore, in order to have high energy storage efficiency, the associated storage system needs to employ a number of phase-change materials (PCMs), with different melting temperatures, in a cascade [9-15]. This poses two challenges:

- There is lack of commercially available and cost effective PCMs to cover the whole operating temperature range.

This paper was recommended for publication in revised form by Regional Editor N. Filiz Ozdil

${ }^{1}$ Energy and Power Engineering Division, School of Energy Environment and Agrifood, Cranfield University, Cranfield, Bedfordshire, MK43 OAL, UK

${ }^{2}$ Department of Mechanical Engineering, Bayero University, Kano, P. M. B. 3011, Nigeria

*E-mail address: mubarak.danladi@gmail.com

Orcid id: 0000-0002-5774-691X

Manuscript Received 23 January 2019, Accepted 23 May 2019 
- Suitable PCMs have very low thermal conductivity of about $0.5 \mathrm{~W} / \mathrm{mK}[11,16]$.

Over the years, three commercially available PCMs $\left(\mathrm{NaNO}_{3}\right.$, eutectic mixture of $\mathrm{KNO}_{3} / \mathrm{KCl}$ and $\left.\mathrm{KNO}_{3}\right)$ have been investigated $[9,17]$ and their suitability and thermo-physical properties have been proven experimentally. Various methods of increasing the apparent thermal conductivity of suitable PCMs has been proposed and tested [18 - 21]. These include: micro encapsulation which involves using a highly conductive material such as graphite to form a PCM composite; macro encapsulation of the PCM in small cylindrical or spherical enclosures, thereby increasing the overall surface area for heat transfer within the storage media; and the use of thermo-syphon tubes (i.e heat pipes) and the use of fins (radial or axial). The use of fins is the most practical approach for storage systems for solar thermal power generation [22 - 27].

The concrete tube register (CTR) storage concept has been investigated with various laboratory-scale units and pilot systems have been successfully operated for temperatures up to $500^{\circ} \mathrm{C}$ [28 - 31]. Concrete offers a low-cost storage system in terms of capital investment and maintenance, wide availability and low environmental impacts [11].

The objective of this study is to conduct analysis of a hybrid three-stage cascaded finned latent-heat storage (LHS) modules assisted with a high-temperature sensible-heat CTR storage stage, for parabolic trough plants using synthetic oil as the HTF, through Simulation. This was carried out, employing the Dymola simulation environment and the "TechThermo" library [32]. Design of a storage system for a $50 \mathrm{MW}_{\mathrm{e}}$ plant was done using fins to tackle the problem of lower thermal conductivity of suitable PCMs, while a CTR was used to cover the operating temperature range of the parabolic trough plants.

\section{THE STORAGE SYSTEM CONFIGURATION}

The storage system consists of three finned LHS modules (each having a different PCM) and a CTR module connected in series (Figure 1a). Each LHS module will be a vertical cylindrical enclosure containing a number of parallel finned tubes (Figure 1b). The cylindrical configuration of the enclosures was selected for its compactness and lower heat losses compared with rectangular enclosures [33]. In a LHS module, the PCM occupies the space between the parallel finned tubes. The CTR module consists of arrays of tubes embedded in a casted concrete (Figure 1b). A storage module can, thus, be considered to consist of storage elements (Figure 1c) placed in parallel. As the performances of individual elements in a storage module are identical, the performance analysis of the modules can be carried out by considering only a single storage element in each module. The analysis of finned LHS modules, conducted by [34], indicated that with HTF-pipe inner and outer diameters of 0.008 and $0.012 \mathrm{~m}$, respectively, a fin outer radius of $0.0488 \mathrm{~m}$, a fin thickness of $0.001 \mathrm{~m}$ and a distance between fins of $0.01 \mathrm{~m}$ results in the best heat flux enhancement. Thus, these values were employed here.

In the finned cascaded LHS modules the three most suitable, experimentally-tested and commercially available $\mathrm{PCMs} \mathrm{NaNO}_{3}, \mathrm{KNO}_{3} / \mathrm{KCl}$ and $\mathrm{KNO}_{3}$ were used. Their thermo-physical properties are presented in table 1. Considerable research has been carried out for developing suitable concrete materials for use in CTRs. A hightemperature concrete (N4-concrete) consisting of blast furnace cement as a binder, heat-resistant gravel and sand, and a polyethylene fibre permeability improver (see table 1) has been tested for over 370 charging-discharging cycles with no degradation in performance [22,29,31]. This was used as the storage material in the CTR considered in this study.

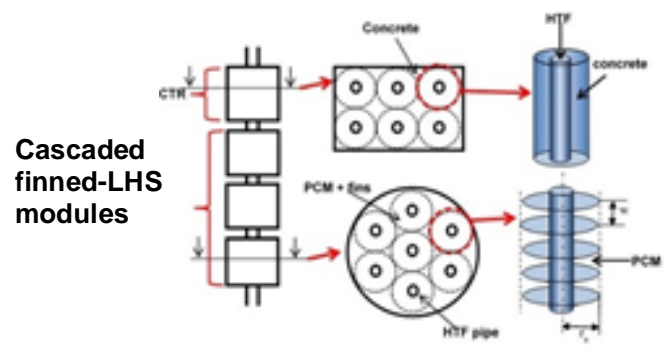

Figure 1. The storage system configuration a) the system, b) cross-section of modules, and c) single storageelement 
Table 1. Thermo-physical properties of suitable PCMs [12, 31]

\begin{tabular}{|c|c|c|c|c|c|c|c|c|}
\hline & \multicolumn{2}{|c|}{$\mathrm{NaNO}_{3}$} & \multicolumn{2}{|c|}{$\begin{array}{c}\mathrm{KNO}_{3} / \mathrm{KCl} \\
(4.5 \% \text { by mass })\end{array}$} & \multicolumn{2}{|c|}{$\mathrm{KNO}_{3}$} & \multicolumn{2}{|l|}{ N4 concrete } \\
\hline & $\begin{array}{l}\text { Solid } \\
@ \quad 20 \\
{ }^{\circ} \mathrm{C}\end{array}$ & $\begin{array}{l}\text { Liquid @ } \\
\text { melting }\end{array}$ & $\begin{array}{l}\text { Solid } \\
@ \\
20^{\circ} \mathrm{C}\end{array}$ & $\begin{array}{l}\text { Liquid } \\
@ \\
\text { melting }\end{array}$ & $\begin{array}{l}\text { Solid } \\
@ \\
20^{\circ} \mathrm{C}\end{array}$ & $\begin{array}{l}\text { Liquid @ } \\
\text { melting }\end{array}$ & Equation & Value range \\
\hline Melting temperature $\left({ }^{\circ} \mathrm{C}\right)$ & & 306 & & 320 & & 335 & & \\
\hline $\begin{array}{llll}\begin{array}{l}\text { Latent heat of fusion } \\
(\mathrm{kJ} / \mathrm{kg})\end{array} & & \\
\end{array}$ & & 171.8 & & 74.4 & & 95.2 & & \\
\hline Density $\left(\mathrm{kg} / \mathrm{m}^{3}\right)$ & 2261 & 1910 & 2100 & 1850 & 2109 & 1870 & & 2250 \\
\hline $\begin{array}{l}\begin{array}{l}\text { Specific } \\
(\mathrm{kJ} / \mathrm{kgK})\end{array} \\
\text { heat capacity }\end{array}$ & 1.096 & 1.823 & 1.21 & 1.21 & 953 & 1342 & $0.7+8.75 \times 10^{-4} T\left({ }^{\circ} \mathrm{C}\right)$ & $720-1050$ \\
\hline $\begin{array}{l}\text { Thermal conductivity } \\
(\mathrm{W} / \mathrm{mK})\end{array}$ & 0.495 & 0.565 & 0.48 & 0.48 & 0.5 & 0.459 & $1.467-6.667 \times 10^{-4} \mathrm{~T}\left({ }^{\circ} \mathrm{C}\right)$ & $1.45-1.2$ \\
\hline $\begin{array}{ll}\begin{array}{l}\text { Dynamic } \\
(\mathrm{kg} / \mathrm{ms})\end{array} & \text { viscosity } \\
\end{array}$ & & $3.02 \times 10^{-3}$ & & & & $2.97 \times 10^{-3}$ & - & \\
\hline $\begin{array}{l}\text { Thermal expansion } \\
\text { coefficient }(1 / \mathrm{K})\end{array}$ & & $3.65 \times 10^{-4}$ & & & & $4.16 \times 10^{-3}$ & - & $11.6 \times 10^{-6}$ \\
\hline Volume expansion (\%) & & 10.7 & & 14.1 & & 3.3 & - & - \\
\hline
\end{tabular}

\section{MODELLING}

\section{Cascaded Finned Latent Heat Storage (LHS) Model}

In the modelling, a single finned-LHS element was considered (Figure1c). To capture the changes in the temperature of the HTF as it flows through the HTF-pipe, the element was divided into differential axial segments of length dz (Figure 2a). In each axial segment (Figure 2b), the heat transfer was assumed to be one dimensional in the radial direction. The heat transfer in and out of the finned annular gap was estimated by using an effective heat transfer coefficient obtained using CFD considering a single finned annular gap [35, 36]. Finned segments (Figure 2b) are placed in series to form a finned LHS element. The finned LHS elements of the three cascaded LHS modules are then connected in series to form a complete cascaded finned LHS element.

The finned segment model is divided into two sub-models:

- The HTF-flow in pipe model

- The finned annular gap model

Dymola, a simulation environment based on the Modelica language, capable of determining the dynamic behaviour of technical systems, allows the building of individual physical models that can be combined together to form a complete model [37]. Figure 2 presents the structure of the finned segment model. The thermo-physical properties of both the HTF and PCM are inputs to the HTF and annular gap models, respectively.
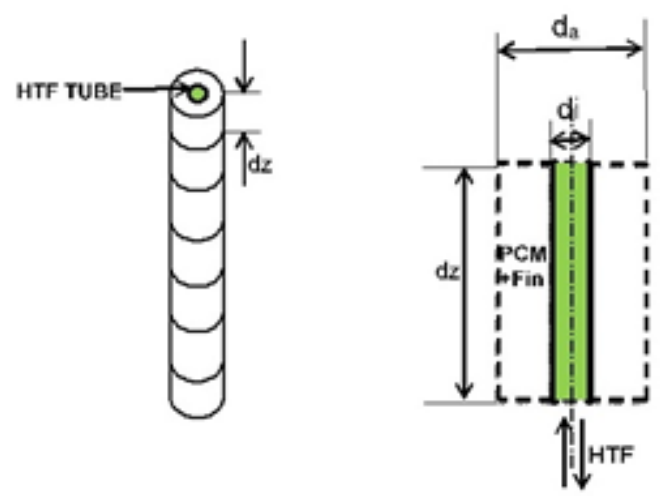

Figure 2. Physical model of the finned storage element 


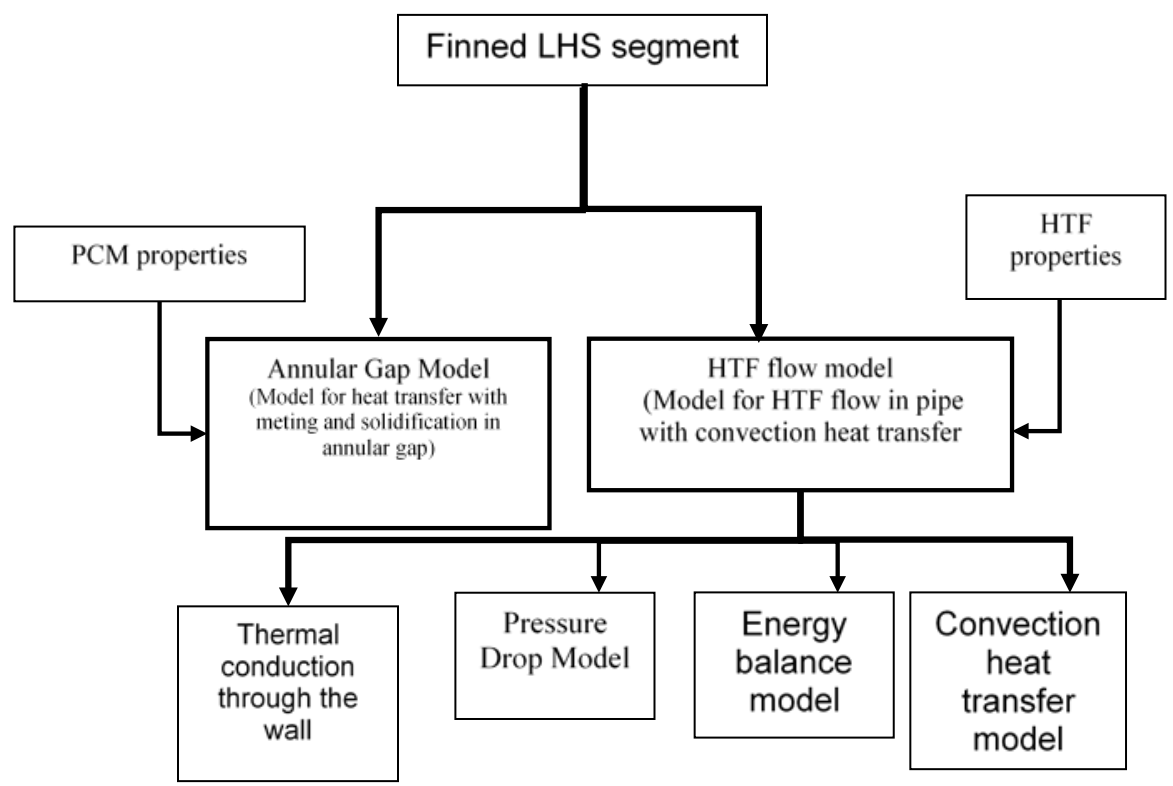

Figure 3. Structure of the finned segment model

\section{HTF-Flow in Pipe Model}

In the HTF-flow in pipe model, the heat absorbed or released by the HTF in the pipe due to forced convection and conduction through the HTF-pipe wall is calculated. The energy balance of the HTF flow is given by:

$$
\dot{m} c_{p, h t f}\left(T_{h t f, \text { in }}-T_{h t f, \text { out }}\right)=\dot{Q}+m_{h t f} c_{p, h t f} \frac{d T_{h t f}}{d t}
$$

where,

$$
T_{h t f}=\frac{T_{h t f, \text { in }}+T_{h t f, o u t}}{2}
$$

The first term on the right-hand side of equation (1) represents the heat transferred through the wall to the PCM given by:

$$
\dot{Q}=h_{f c} 2 \pi r_{i} d z\left(T_{h t f}-T_{w i}\right)=2 \pi d z k_{w}\left(\frac{T_{w i}-T_{w o}}{\ln \left(\frac{r_{o}}{r_{i}}\right)}\right)
$$

The second term on the right-hand side of equation (1) represents the time rate of change of the enthalpy of the HTF due to the change in its mean temperature. This term was neglected in order to simplify the model since its effect will be cancelled out over a complete charging-discharging cycle. The thermo-physical properties of the HTF (i.e. Therminol VP-1) were obtained, as functions of temperature, from Solutia [38].

\section{Finned Annular Gap Model}

The fins attached to the outer surface of a HTF pipe contribute to the increase in the effective heat transfer into/out of the PCM. In the modelling of the finned annular gap, it will be assumed that the PCM occupies the annular gap exchanging heat with the HTF flowing through the pipe only in the radial direction. At the start of charging, the PCM is at a temperature lower than its melting point and heat transferred from the HTF increases the temperature of the PCM until the melting point is reached. The average PCM temperature remains almost constant until all the PCM has melted. After the complete melting, the average PCM temperature starts to increase until there is no driving temperature difference. The discharging process is the reverse of the charging process. The effective heat capacity method [39] was employed in modelling the heat exchange during phase change. The phase change was assumed to occur over a small range of temperature $\Delta T_{m}$. Thus, the specific heat capacity during phase change is given by: 


$$
c_{p, p c m, m}=\frac{\lambda}{T_{\text {liquid }}-T_{\text {solid }}}+\frac{c_{p, p c m, s}+c_{p, p c m, l}}{2}
$$

The transient change in the temperature of the PCM is calculated from:

$$
\dot{Q}=m c_{p, p c m} \frac{d T_{p c m}}{d t}
$$

where,

$$
c_{p, p c m}=\left\{\begin{array}{cc}
c_{p, p c m, s} & T_{p c m}<T_{\text {solid }} \\
c_{p, p c m, m} & T_{\text {solid }}<T_{p c m}<T_{\text {liquid }} \\
c_{p, p c m, l} & T_{p c m}>T_{\text {liquid }}
\end{array}\right.
$$

To avoid discontinuities, the change in specific heat capacity from one phase to the other was assumed be linear. The heat transfer rate from the HTF pipe surface was calculated using:

$$
\dot{Q}=h A\left(T_{w o}-T_{p c m}\right)
$$

The effective heat transfer coefficient $(h)$ during the charging and the discharging processes were obtained by [35] and [36] using CFD simulations by considering a single finned annular gap. For the charging process the quasi-stationary heat transfer coefficient is presented by equations (7)-(9) for the three PCMs considered. For the discharging process, the effective heat transfer coefficient during solidification was found to vary linearly with liquid fraction and the HTF mass flow rate, and was represented by equation (10).

$$
\begin{gathered}
h_{m, \mathrm{NaNO}_{3}}=1391.6(\dot{m})+933.64 \\
h_{m, \mathrm{KNO}_{3} / K C l}=1363.6(\dot{m})+744.51 \\
h_{m, \mathrm{KNO}_{3}}=1409.4(\dot{m})+715.93 \\
h_{s}=a(\beta)+c
\end{gathered}
$$

where,

and

$$
a=224.04(\dot{m})+20.265
$$

$$
c=1395.4(\dot{m})+267.96
$$

\section{The Concrete Tube Register (CTR)}

The CTR segment consists of the HTF pipe and the concrete annular gap (Figure 1). In order to increase the model's numerical accuracy, the concrete annular gap was divided into radial elements. The transient heat transfer into or out of each radial element was calculated using one-dimensional transient conduction, considering the annular gap as a hollow cylinder. Thus, the energy balance for each radial element, i, is given by:

$$
\dot{Q}_{i, n e t}=m_{i} c_{\text {conc }} \frac{d T_{i}}{d t}
$$

where $\dot{Q}_{i, n e t}$ is the net heat transfer rate into the radial element from neighbouring elements.

\section{ANALYSIS}

The complete model of the HCSS element was formed by joining the cascaded finned LHS elements of the three LHS modules in series with that of the CTR element. In a solar thermal power plant, the storage system will be connected parallel to the solar field; therefore, the bottom of the cascaded finned-LHS will be connected 
to the inlet of the solar field while the top of the CTR will be connected to the outlet of the solar field. The boundary conditions of the storage system are thus:

Charging:

Inlet temperature of $\mathrm{HTF}$ (top) $=393^{\circ} \mathrm{C}$ (Outlet temperature from the solar field)

Outlet temperature of HTF (bottom) $=290-330^{\circ} \mathrm{C}$ (To avoid overheating of the HTF in the solar field) Discharging:

Inlet temperature of HTF (bottom) $=286^{\circ} \mathrm{C}$ (power block outlet temperature at design point)

Outlet temperature of $\mathrm{HTF}$ (bottom) $\geq 350^{\circ} \mathrm{C}$ (This is the minimum temperature for turbine operation)

\section{Individual Finned LHS Module Lengths}

From the heat transfer point of view (i.e. heat exchanger design) the length of each module must be selected to achieve the minimum temperature difference at the end of the cascaded module (terminal temperature difference), typically $1-5^{\circ} \mathrm{C}$. The smaller the terminal temperature difference $\left(T_{h t f}-T_{m}\right)$ the higher the required length of the module. Thus, a compromise needs to be made in selecting a suitable length of the module and the terminal temperature difference. Considering sodium nitrate module, a HTF inlet temperature of $286^{\circ} \mathrm{C}$ and mass flow rate of $0.03 \mathrm{~kg} / \mathrm{s}$, and initial PCM temperature of $1^{\circ} \mathrm{C}$ above melting point of the PCM, simulations were conducted considering different length of the module, or HTF-pipe, from 5 to $17.5 \mathrm{~m}$. Figure 4 presents the variation of terminal temperature difference and effectiveness of the module with the HTF-pipe length. The effectiveness was calculated using the relation:

$$
\text { effectiveness }=\frac{\text { average heat transfer rate during phase change }}{\text { maximum posible heat transfer rate }}=\frac{\dot{Q}_{\text {ave,pc }}}{\dot{m}_{h t f} c_{p, h t f}\left(T_{i n, h t f}-T_{m}\right)}
$$

From Figure 4, it can be concluded that the terminal temperature difference is an inverse exponential function of the HTF-pipe length and a $4-5^{\circ} \mathrm{C}$ temperature difference can be a compromise with a corresponding heat exchanger effectiveness of 0.75 to 0.8 . Since the main mode of heat transfer during the discharging process is conduction the HTF-pipe lengths for the other two PCM modules are expected to be same as that for the sodium nitrate module. A $5^{\circ} \mathrm{C}$ terminal temperature difference corresponding to finned-LHS module length of $10 \mathrm{~m}$ was selected as a good compromise.

\section{Cascaded Fined LHS Length}

Considering a terminal temperature difference of $5^{\circ} \mathrm{C}$, corresponding to a $10 \mathrm{~m}$ length for each finnedLHS module, simulation was conducted for the cascaded finned-LHS for the discharging process. Each PCM is assumed to be initially at $20 \mathrm{~K}$ above its melting temperature and a length of each axial segment of $0.6 \mathrm{~m}$ was used.

Figure 5 presents the variation of the HTF outlet temperature at the end of the cascaded finned-LHS with time. Initially the HTF temperature reduces rapidly due to the decrease in the average temperature of the overheated PCM; it then becomes constant for a period of time before starting to reduce slowly until the end of the 6 hours discharging time. A stable HTF temperature of $328^{\circ} \mathrm{C}$ was obtained for about 3.5 hours from the beginning of discharging. The slow reduction in the HTF outlet temperature signifies the reduction in the heat flux as the solidification process progresses. From Figure Figure 6 it can be observed that the PCMs in modules 2 and 3 solidified faster than the PCM in module 1 with a rate inversely proportional to the latent heat of fusion of the PCM. The liquid fraction for PCM in module1 $\left(\mathrm{NaNO}_{3}\right)$ is higher due to its higher latent heat of fusion and at the end of discharging (6 hours) there is still remaining 30\% unsolidified PCM.

This indicated that the latent heat of fusion of each PCM should be considered in the design. There is need to consider changing the length of each element based on different criteria and examine the impact on capacity utilisation. Thus, other methods of dividing the total cascade length between the three PCM modules were considered. Using a total cascade length of $30 \mathrm{~m}$, the cascade was then divided using the following criteria: 
- $\quad$ Case 1: module length proportional to the latent heat of fusion of the PCM (i. e. $A \propto \lambda$ ). This result in a cascade with module-length ratio of 25:11:14 corresponding to $\mathrm{NaNO}_{3}, \mathrm{KNO}_{3} / \mathrm{KCl}$ and $\mathrm{KNO}_{3} \mathrm{PCMs}_{\text {, }}$ respectively.

- Case 2: the length is adjusted such that the same storage capacity in achieved in each module (i. e. $m_{p c m} \lambda=$ constant). This results in a module-length ratio of 11:22:17.

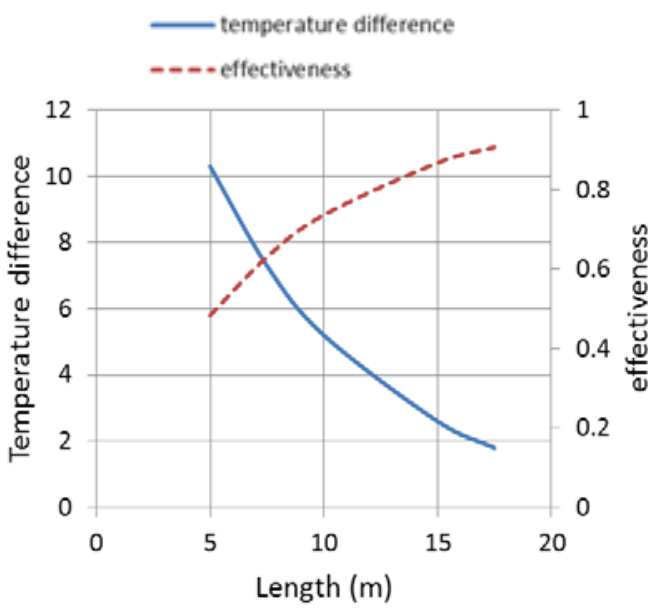

Figure 4. Variation of terminal temperature difference and effectiveness with HTFpipe length for the $\mathrm{NaNO}_{3}$ module

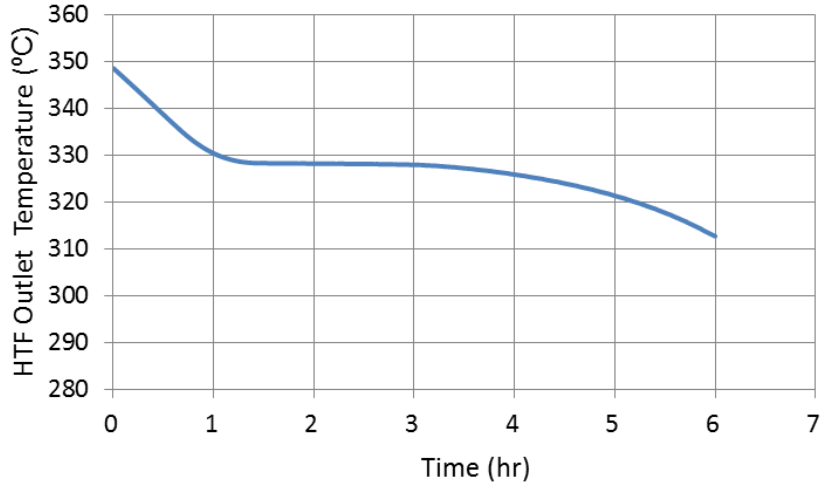

Figure 5. HTF outlet temperatures for a complete three stage cascade using equal module length of $10 \mathrm{~m}$ and $\mathrm{HTF}$ inlet temperature of $286^{\circ} \mathrm{C}$

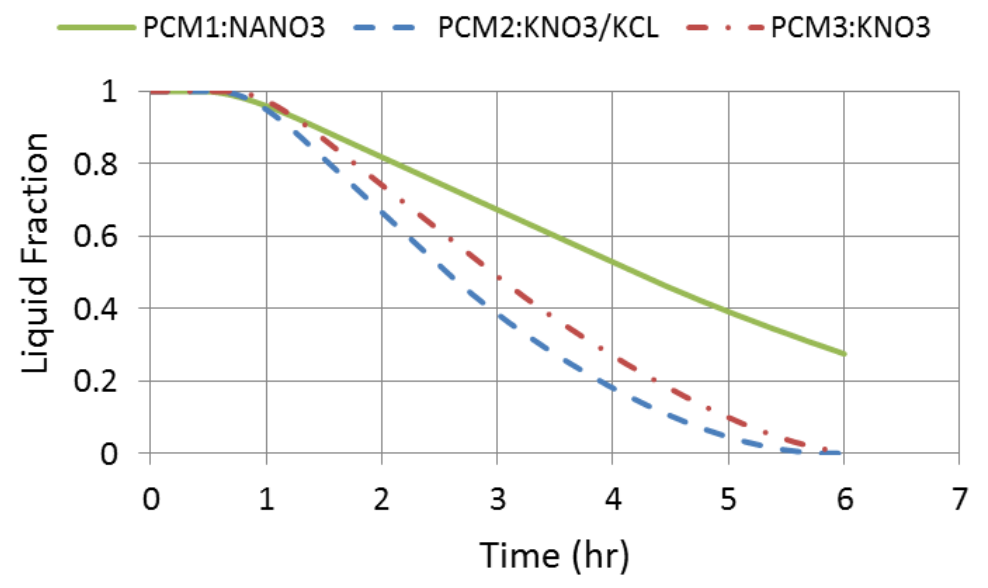

Figure 6. Liquid fraction for each PCM module in the cascade system

Simulations were then conducted based on the criteria described. Table 2 presents the element theoretical storage capacity and the length of each finned LHS module using each of the criteria. The element theoretical storage capacity was calculated considering the latent and sensible heat capacity for $20 \mathrm{~K}$ temperature difference above and below the melting point of each PCM.

Figure 7 presents the HTF outlet temperature and heat discharged comparisons of the three cases. It can be seen that using same capacity in each module (Case 2) produced higher HTF outlet temperatures. Figure 7(b) indicates that although Case 2 has the lowest theoretical element storage capacity (Table 2), it has the highest actual storage capacity (i.e. the amount of heat discharged) and consequently the highest utilisation factor. This thus makes splitting the total length of the cascade based on same storage capacity in each module to be the best option in terms of storage capacity and PCM utilisation.

Finally, the following procedure for the design of the cascaded finned LHS is proposed: 
- First a terminal temperature difference is selected

- Based on the terminal temperature difference, the length of each module can be determined and the total length of the cascade obtained

- The total length of the cascade is then divided based on having the same storage capacity in each module to obtain the final length of each module.

Table 2. Theoretical capacity and the length for each cascade corresponding to each criterion

\begin{tabular}{|l|l|l|l|l|l|l|}
\hline \multirow{2}{*}{ PCM } & \multicolumn{9}{l}{$\begin{array}{l}\text { Element theoretical storage capacity } \\
\text { (MJ) }\end{array}$} & \multicolumn{3}{l|}{ Module length (m) } \\
\cline { 2 - 8 } & Case 1 & Case 2 & Case 3 & Case 1 & Case 2 & Case 3 \\
\hline $\mathrm{NaNO}_{3}$ & 48.37 & 21.28 & 32.25 & 15 & 6.6 & 10 \\
\hline $\mathrm{KNO}_{3} / \mathrm{KCl}$ & 12.54 & 25.08 & 19.00 & 6.6 & 13.2 & 10 \\
\hline $\mathrm{KNO}_{3}$ & 18.96 & 23.02 & 22.57 & 8.4 & 10.2 & 10 \\
\hline Total & 79.88 & 69.39 & 73.82 & 30 & 30 & 30 \\
\hline $\begin{array}{l}\text { Case 1: using length proportional to latent heat of fusion } \\
\text { Case 2: using same capacity in each module } \\
\text { Case 3: using same length (heat exchange point of view) }\end{array}$ \\
\hline
\end{tabular}

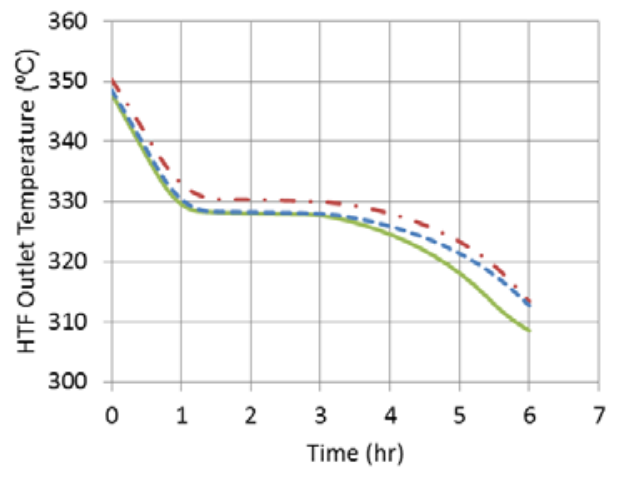

a)

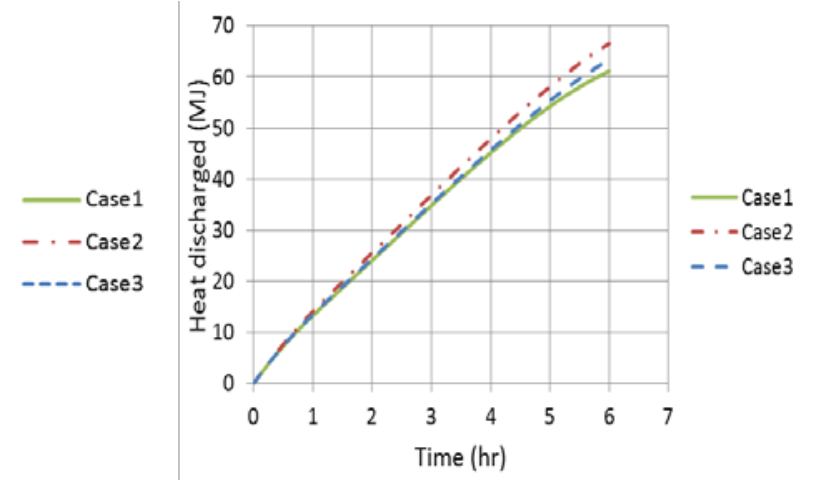

b)

Figure 7. a) HTF outlet temperature, b) heat discharged comparisons for cases 1,2 and 3

\section{Design of Complete Storage System}

In the previous section, the total length of the cascaded finned LHS of $30 \mathrm{~m}$ distributed with the ratio 11:22:17 between the three successive modules was obtained. For the CTR, HTF pipes with the same inner and outer diameters as those employed in the cascaded finned LHS modules were employed and an outer diameter of $0.08 \mathrm{~m}$ for the CTR element was considered to minimise the radial temperature gradient at the end of charging.

A segment length of $2.5 \mathrm{~m}$ was used. A CTR length of $130 \mathrm{~m}$ was found to satisfy the storage system boundary conditions for a 12-hour charging-discharging cycle and a periodically balanced state (state at which subsequent charging and discharging cycles becomes similar) was reached after 10 cycles.

Figure8 presents the variation of cumulative heat transferred to/from the PCM with time during charging and discharging respectively for the cascade and the CTR element for the $10^{\text {th }}$ cycle. The total storage capacity of the HCSS element is $129.23 \mathrm{MJ}$, of which $44 \%$ (57.26 MJ) is that of the cascaded finned LHS elements and the rest (56\%) is from the CTR element. The cascaded finned LHS elements provide less than $50 \%$ of the total storage capacity. This is undesirable as it will limit the potential of the latent heat storage. Thus, there is need for exploring whether the percentage capacity provided by the cascade can be increased.

The total length of the cascade was increased to $36 \mathrm{~m}$. Simulations were conducted with CTR lengths of $80 \mathrm{~m}, 90 \mathrm{~m}$ and $120 \mathrm{~m}$ for 12 hours charging-discharging cycle in order to determine the length of the CTR that will satisfy the required boundary conditions. Figure 9 presents the HTF outlet temperature during charging and discharging at the cycle at which subsequent charging discharging cycles becomes similar for the three CTR lengths. A CTR length $120 \mathrm{~m}$ satisfies the boundary condition requirements. Table 3 presents the performance 
comparisons between a complete storage system with cascade and CTR lengths of $30 \mathrm{~m}$ and $130 \mathrm{~m}$, respectively, with that of corresponding lengths of $36 \mathrm{~m}$ and $120 \mathrm{~m}$. The reduction of $10 \mathrm{~m}(\sim 7.6 \%)$ in length in the CTR resulted in a decrease in its storage capacity and specific storage capacity of $\sim 11 \%$ and $3.5 \%$, respectively. The storage capacity of the cascaded finned-LHS section, increased as its length was increased from $30 \mathrm{~m}$ to $36 \mathrm{~m}$ (i.e. by $\sim 20 \%$ ). However, the specific storage capacity and percentage of PCM that undergoes phase change during a complete charging discharging cycle decreased with increase in the length of the cascade. The $36 \mathrm{~m}$ length of the LHS cascade element storage capacity is greater by only $0.9 \mathrm{MJ}$ (i.e. $0.6 \%$ ). Although the storage capacity ratio of cascade, relative to the total storage capacity of the HCSS, increased from $44 \%$ to $50.4 \%$, increasing the length of the cascade did not result into a higher specific capacity system. As such, $30 \mathrm{~m}$ is the optimum length of the cascade for the HTF mass flow rate of $0.03 \mathrm{~kg} / \mathrm{s}$.

Up to this point, a HTF mass flow rate of $0.03 \mathrm{~kg} / \mathrm{s}$ has been used. The HTF mass flow rate affects the total length required for the storage system to satisfy the boundary conditions and thus determines the actual storage capacity. For each HTF mass flow rate there is corresponding cascade and CTR lengths that will give the maximum specific storage capacity. In view of this, simulations were conducted for cascade lengths ranging from $30 \mathrm{~m}$ to $42 \mathrm{~m}$ and HTF mass flow rates of $0.025 \mathrm{~kg} / \mathrm{s}$ to $0.04 \mathrm{~kg} / \mathrm{s}$. Figure 10 presents a plot of the specific storage capacities considering different cascade length for each of the HTF mass flow rate. The specific capacity depends on the HTF mass flow rate and the length of the storage element. The specific capacity reaches a maximum and then starts to reduce as the length is increased. For each HTF mass flow rate the best cascade length is the one with the highest specific capacity and phase change.

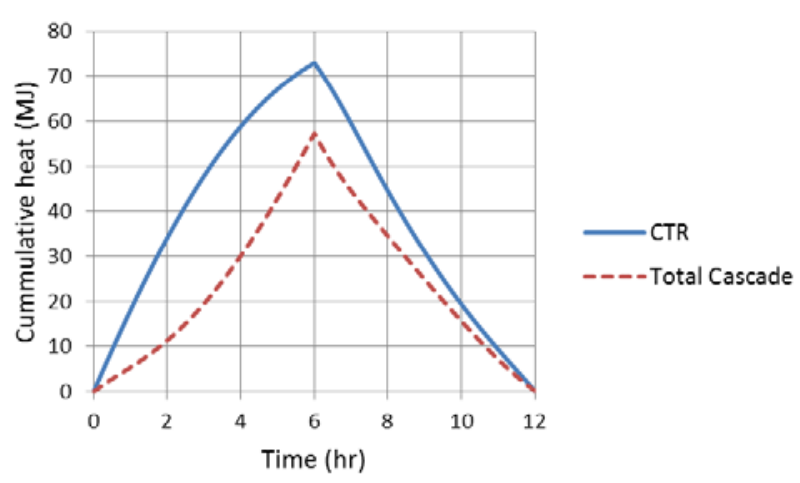

Figure 8. Variation of cumulative heat transferred to/from storage element with time for the $10^{\text {th }}$ cycle

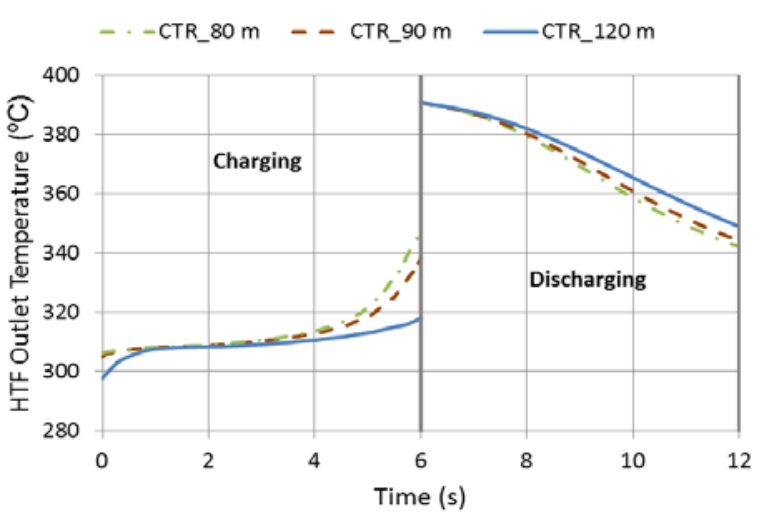

Figure 9. HTF outlet temperature during charging and discharging for CTR lengths of 80, 90 and $120 \mathrm{~m}$

Table 3. Performance comparisons for storage elements with cascade lengths of $30 \mathrm{~m}$ and $36 \mathrm{~m}$

\begin{tabular}{|l|c|c|c|c|}
\hline \multirow{2}{*}{} & \multicolumn{2}{|c|}{$30 \mathrm{~m}$} & \multicolumn{2}{c|}{$36 \mathrm{~m}$} \\
\cline { 2 - 5 } & Cascade & CTR & Cascade & CTR \\
\hline Length (m) & 30 & 130 & 36 & 120 \\
\hline Actual storage capacity (MJ) & 56.8 & 72.4 & 65.5 & 64.5 \\
\hline Storage capacity/unit length (MJ/m) & 1.89 & 0.56 & 1.82 & 0.54 \\
\hline Specific storage capacity (kJ/kg) & 124.01 & 49.75 & 119.28 & 48.02 \\
\hline & & & & \\
Mass of storage material (kg) & 457.8 & 1455.6 & 549.34 & 1343.6 \\
\hline $\begin{array}{l}\text { Percentage of storage material phase } \\
\text { change (mphase change) } / \mathrm{m}_{\text {total }} \text { \% }\end{array}$ & 87.6 & & & \\
\hline Percentage of total element capacity (\%) & 44 & 56 & 50.4 & 49.6 \\
\hline
\end{tabular}




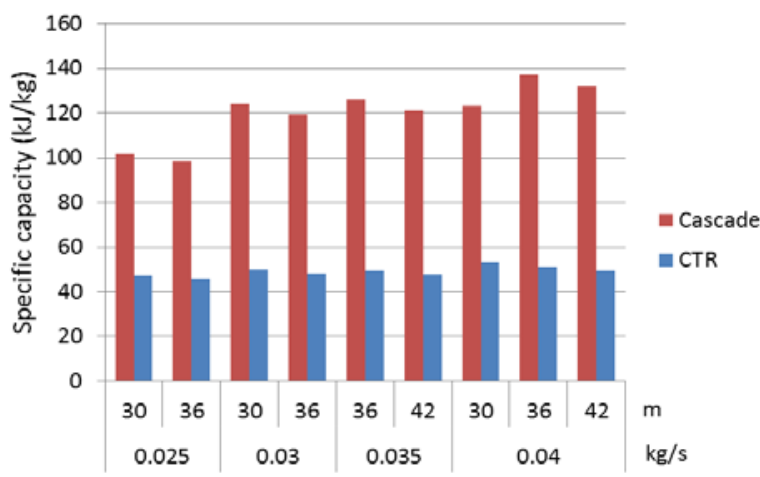

Figure 10. Effect of element HTF mass flow rate and cascade length on specific storage capacity of the cascade and the CTR

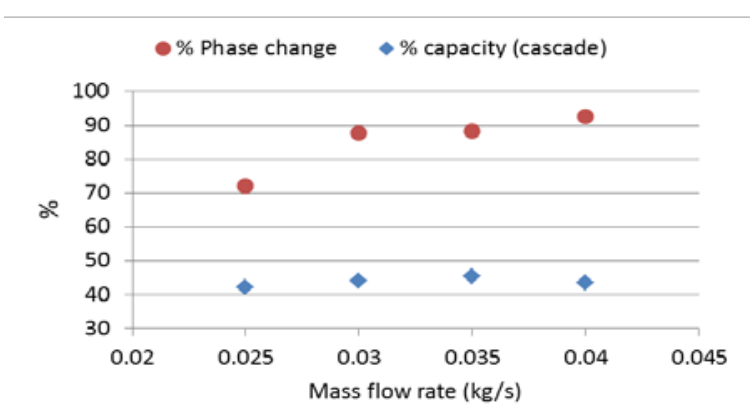

Figure 11. Effect of element HTF mass flow rate on percentage phase change and percentage capacity of cascade

\section{Selection of Storage Element Design HTF Mass Flow Rate}

Since the storage capacity of an element of the storage system depends on the mass flow rate of the HTF and the single element storage capacity determines the total number of storage elements required for a particular total storage capacity, the selection of design mass flow rate must consider the capacity of the whole storage system (not a single element). For a 50 MWe parabolic-trough solar power plant (Andasol 1 type), a thermal storage system with a capacity of $875 \mathrm{MWh}_{\mathrm{th}}$ is required for 6 hour discharging operation (Michels and Pitzpaal, 2007). Table 4 presents the calculated number of storage elements required and total storage system HTF mass flow rate for the different single element HTF mass flow rates. Although the single element HTF mass flow rate increases from $0.03 \mathrm{~kg} / \mathrm{s}$ to $0.04 \mathrm{~kg} / \mathrm{s}$, the total required HTF mass flow rate for the $875 \mathrm{MWh}_{\text {th }}$ storage capacity, for 0.035 $\mathrm{kg} / \mathrm{s}$ and $0.04 \mathrm{~kg} / \mathrm{s}$ single element HTF mass flow rates are lower than that for $0.03 \mathrm{~kg} / \mathrm{s}$. This is because the single element storage capacity increases with the increase in its HTF mass flow rate, leading to lower number of storage elements required to fulfil the total storage capacity. Figure 11 presents the percentage contribution of the PCM cascade to the total storage capacity of the HCSS and the percentage PCM phase change produced by the cascade. This was calculated by multiplying the element percentage phase change with the number of required elements. The percentage phase change shows the percentage utilization of the PCM in each case. Storage element HTF mass flow rates of 0.03 and $0.035 \mathrm{~kg} / \mathrm{s}$ have almost equal percentage phase change and the percentage capacity of the cascade increases and then decreases with a maximum at an element HTF mass flow rate of $0.035 \mathrm{~kg} / \mathrm{s}$. A single element HTF mass flow rate of $0.035 \mathrm{~kg} / \mathrm{s}$ was then selected as the design HTF mass flow rate for maximising the percentage capacity of the PCM cascade.

\section{HCSS Size for 6 Hour Storage Capacity}

The cascade and CTR lengths of $36 \mathrm{~m}$ and $150 \mathrm{~m}$, respectively, were obtained as the best values that satisfy the boundary conditions of the parabolic-trough solar power plant for single element HTF mass flow rate of $0.035 \mathrm{~kg} / \mathrm{s}$ to maximise the percentage capacity of the PCM cascade. For these values, the storage capacity of an element of the HCSS is 152.24 MJ. For an 875 MWh $_{\text {th }}$ storage capacity system, 20,691 storage elements in parallel will be required.

\section{The Cascaded Finned LHS modules}

The storage-elements for each finned-LHS module will be arranged in a cylindrical enclosure in a staggered arrangement in order to have compact module. A cylindrical enclosure with a diameter of $16.3 \mathrm{~m}$ will accommodate the 20,691 storage elements allowing for extra space for construction tolerances between elements. Table 5 presents the dimensions and the storage material requirement for the cascaded finned LHS modules. The height of each module was calculated considering the volume of solid PCMs, PCM expansion, the dimensions of the fins and assuming a total header height of $0.1 \mathrm{~m}$. The net volume of each module represents the volume of the storage excluding the header volume and the gross represent that including the header volume. The storage material requirement for each module was also presented. The net storage material volume was calculated considering the active amount of PCM within the fins while the gross volume of storage material includes the volume between 
storage-elements. The cascade provides $45.5 \%$ of the total capacity of the entire storage system with a gross volumetric specific capacity of $43.75 \mathrm{kWh} / \mathrm{m}^{3}$.

Table 4. Total HTF mass flow rate and pumping power for $875 \mathrm{MWh}_{\mathrm{th}}$ capacity HCSS

\begin{tabular}{|l|c|c|c|c|}
\hline \multirow{2}{*}{} & \multicolumn{4}{|c|}{ Storage element HTF mass flow rate (kg/s) } \\
\cline { 2 - 5 } & $\mathbf{0 . 0 2 5}$ & $\mathbf{0 . 0 3}$ & $\mathbf{0 . 0 3 5}$ & $\mathbf{0 . 0 4}$ \\
\hline Length of cascade (m) & 30 & 30 & 36 & 36 \\
\hline Length of CTR (m) & 120 & 130 & 150 & 170 \\
\hline Element storage capacity (MJ) & 110.49 & 129.2 & 152.24 & 173.11 \\
\hline $\begin{array}{l}\text { number of storage elements for 6 } \\
\text { hours storage capacity }\end{array}$ & 28509 & 24381 & 20691 & 18197 \\
\hline $\begin{array}{l}\text { Total storage system HTF mass } \\
\text { flow rate (kg/s) }\end{array}$ & 713 & 731 & 724 & 728 \\
\hline Total pressure drop (bar) & 0.78 & 1.15 & 1.75 & 2.45 \\
\hline pumping power (kW) & 71.27 & 107.84 & 162.48 & 228.62 \\
\hline
\end{tabular}

Table 5. Cascaded LHS module dimensions and storage capacities

\begin{tabular}{|c|c|c|c|c|}
\hline & \multicolumn{4}{|c|}{ PCM } \\
\hline & $\mathrm{NaNO}_{3}$ & $\mathrm{KNO}_{3} / \mathrm{KCl}$ & $\mathrm{KNO}_{3}$ & Total \\
\hline \multicolumn{5}{|c|}{ Storage material } \\
\hline Net volume of storage material $\left(\mathrm{m}^{3}\right)$ & 1207 & 2415 & 1866 & 5489 \\
\hline $\begin{array}{l}\text { Gross volume of storage material } \\
\left(\mathrm{m}^{3}\right)\end{array}$ & 1634 & 3268 & 2526 & 7428 \\
\hline $\begin{array}{l}\text { Gross mass of storage material } \\
\text { (tonne) }\end{array}$ & 3694.8 & 6863.4 & 5326.3 & 15884.6 \\
\hline \multicolumn{5}{|c|}{ Storage modules } \\
\hline $\begin{array}{l}\text { Length of module including header } \\
\text { (m) }\end{array}$ & 9.74 & 19.98 & 14.01 & \\
\hline Diameter of storage module (m) & \multicolumn{3}{|c|}{16.3} & \\
\hline Net volume of storage module $\left(\mathrm{m}^{3}\right)$ & 2012.48 & 4148.57 & 2902.28 & 9063.33 \\
\hline $\begin{array}{l}\text { Gross volume of storage module } \\
\left(\mathrm{m}^{3}\right)\end{array}$ & 2022.9 & 4159 & 2912.7 & 9094.6 \\
\hline Storage capacity $\left(\mathrm{MWh}_{\mathrm{th}}\right)$ & 94.41 & 152.18 & 151.32 & 397.91 \\
\hline$\%$ of HCSS storage capacity & 10.8 & 17.4 & 17.2 & 45.5 \\
\hline $\begin{array}{l}\text { Gross volumetric specific capacity } \\
\left(\mathrm{kWh}_{\mathrm{th}} / \mathrm{m}^{3}\right)\end{array}$ & 46.67 & 36.59 & 51.95 & 43.75 \\
\hline
\end{tabular}

\section{Concrete Tube Register (CTR)}

A total volume of CTR of $15,800 \mathrm{~m}^{3}$ is required (excluding space between adjacent elements) to provide the required $54.5 \%$ of the total storage capacity. Considering that the storage length is $150 \mathrm{~m}$, the crosssectional area of the CTR that will fit 20,691 parallel pipes in a staggered arrangement is $4.2 \times 27.6 \mathrm{~m}$, the gross storage volume of the CTR is $17,388 \mathrm{~m}^{3}$. This CTR can be built of small modular units since the construction as a single 
unit is impossible and unreasonable [30]. The calculated gross volumetric specific capacity of $27.4 \mathrm{kWh} / \mathrm{m}^{3}$ is similar to that obtained experimentally by [30] $\left(26.6 \mathrm{kWh} / \mathrm{m}^{3}\right)$.

\section{Heat Losses}

In the simulation, heat losses from the storage modules to the surrounding were not considered. In this section, these losses will be estimated. Heat losses will reduce the actual capacity of the storage system and thus the amount of losses needs to be known in order to increase the capacity to compensate for the losses.

\section{The Cascaded Finned LHS}

An empirical heat lost equation giving the heat loss per unit surface area of a storage tank was developed by Herrmann et al. (2004) following empirical relationship for estimating the rate of heat loss from the two-tank molten-salt storage system employed in Solar Two solar power plant in California, USA[40]:

$$
\dot{q}_{\text {loss }}=0.00017 \times T_{\text {salt }}+0.012 \mathrm{~kW} / \mathrm{m}^{2}
$$

where $\mathrm{T}_{\text {salt }}$ is the average temperature in the storage tank.

This relationship was used in estimating the daily heat loss (since the cycle of operation of the integrated storage system with plant is 24 hours) from each of three finned LHS modules using the average storage temperature (i.e. temperature at the end of charging) and the surface area, of each module. The total daily heat loss for the three modules was $5.774 \mathrm{MWh}_{\mathrm{th}}$. This represents only $1.45 \%$ of the cascaded finned LHS total storage capacity, and therefore, will not have a considerable impact in the performance of the system.

\section{Concrete Tube Register}

The daily heat loss for the CTR was estimated by employing the relationship developed by [41]:

$$
\dot{q}_{\text {loss }}=0.1669 \times\left(T_{\text {conc }}-T_{a m b}\right)^{1.201}
$$

Considering an average temperature of the CTR at the end of charging of $384^{\circ} \mathrm{C}$ and an ambient temperature of $25^{\circ} \mathrm{C}$, the maximum daily heat loss of $45.87 \mathrm{MWh}_{\mathrm{th}}$, corresponding to $9.6 \%$ of the CTR storage capacity was obtained. The heat loss can be compensated for by increasing the size of the CTR module by $10 \%$.

\section{COMPARISON WITH THE TWO-TANK, MOLTEN-SALT, SENSIBLE-HEAT STORAGE SYSTEM}

For storage capacity of 875 MWhth, the commercially available two-tank, sensible-heat, molten-salt storage system has a total volume of $30,847.88 \mathrm{~m} 3$ with an active salt inventory of 26 ktonne [12, 42]. The volumetric specific capacity of the system is $28.36 \mathrm{kWh} / \mathrm{m} 3$. For the HCSS investigated here, the total volumetric specific capacity is $31 \mathrm{kWh} / \mathrm{m} 3$. Although the volumetric specific capacity of the solid sensible-heat CTR storage is low, the total volumetric specific capacity of the entire HCSS is greater than that of the two-tank system by about $9.3 \%$. This, therefore shows that the designed storage system is a more compact than the two-tank system. The volumetric specific capacity of the three-stage cascaded finned LHS modules is $\sim 44 \mathrm{kWh} / \mathrm{m} 3$. This is greater than that of the two-tank system by $54 \%$. This indicates the potential of the cascaded finned LHS in reducing the size of the storage system.

\section{CONCLUSIONS}

A hybrid cascaded latent/sensible storage system for a $50 \mathrm{MW}_{\mathrm{e}}$ parabolic-trough solar power plant using synthetic oil as HTF was analysed. Due to the limited availability of PCMs to cover the entire temperature range of operation of the solar power plant, a sensible-heat CTR module was added to the cover the temperature range $>335^{\circ} \mathrm{C}$. The cascaded finned-LHS provides $45.5 \%$ of the total storage capacity. Daily heat losses from cascaded finned LHS modules are negligible, but represent $\sim 10 \%$ of the storage capacity for the CTR. The three-stage cascaded finned LHS has a volumetric specific capacity of $54 \%$ greater than that of the commonly-employed twotank, sensible-heat storage system. This demonstrates the potential of the cascaded finned LHS to provide a more compact storage system. There is a need for the development of new PCMs with melting temperature between 
$335^{\circ} \mathrm{C}$ and $380^{\circ} \mathrm{C}$ and also other eutectic mixtures of salts having a high latent heat of fusion (similar to that of sodium nitrate). This will reduce the required size and the cost of the storage system considerably.

\section{NOMENCLATURE}

A Outer surface area of the HTF pipe, $\mathrm{m}^{2}$

$c_{p} \quad$ Specific heat capacity, $\mathrm{J} / \mathrm{kgK}$

$\mathrm{dz} \quad$ Height of a storage segment, $\mathrm{m}$

$\mathrm{h} \quad$ Heat transfer coefficient in the annular gap or $\mathrm{PCM}, \mathrm{W} / \mathrm{m}^{2} \mathrm{~K}$

k Thermal conductivity, $\mathrm{W} / \mathrm{mK}$

m Mass, kg

$\dot{m} \quad$ Mass flow rate of the HTF, $\mathrm{kg} / \mathrm{s}$

$\dot{q} \quad$ Heat flux, $\mathrm{W} / \mathrm{m}^{2}$

$\dot{Q} \quad$ Heat transfer rate through the HTF pipe wall, W

$r_{0} \quad$ Outer radius of the HTF pipe, $m$

$r_{i} \quad$ Inner radius of the HTF pipe, $m$

T Average temperature, ${ }^{\circ} \mathrm{C}$

$T_{m} \quad$ Melting temperature of the PCM, ${ }^{\circ} \mathrm{C}$

$T_{\text {solid }} \quad$ PCM temperature at the start of melting, ${ }^{\circ} \mathrm{C}$

$T_{\text {liquid }} \quad$ PCM temperature at the end of melting, ${ }^{\circ} \mathrm{C}$

Greek symbols

$\beta \quad$ Liquid fraction in the PCM

$\lambda \quad$ Latent heat of fusion of the PCM, J/kg

Subscripts

amb Ambient

conc Concrete

fc Forced convection

htf Heat transfer fluid

l Liquid

m Melting

pcm Phase-change material

s Solid

w HTF-pipe wall

wi Inner surface of the HTF-pipe

wo Outer surface of the HTF-pipe

\section{REFERENCES}

[1] De Laquil, P., Kearney, D., Geyer, M. and Diver, R. (1993). Solar-Thermal Electric Technology", in Renewable energy: sources for fuels and electricity, Earthscan, London, pp. 213-296.

[2] Marquez, C. (2008), An Overview of CSP in Europe, North Africa and the middle East, CSP Today

[3] ENEA (2011), Renewable Energy Sources, available at: www.enea.it (accessed 12/05/2014).

[4] Eck, M. and Zarza, E. (2006). Saturated steam process with direct steam generating parabolic troughs, Solar Energy, 80 (11), 1424-1433. https://doi.org/10.1016/j.solener.2006.03.011

[5] Zarza, E., Rojas, M. E., González, L., Caballero, J. M. and Rueda, F. (2006). INDITEP: The first precommercial DSG solar power plant, Solar Energy, 80 (10), 1270-1276. https://doi.org/10.1016/j.solener.2005.04.019

[6] Zarza, E., Lopez, C. W., Camara, A., Martinez, A., Burgaleta, J. I., Martin, J. C. and Fresneda, A. (2008), Almeria GDV- The first solar power plant with direct steam generation.", 14th Biennial CSO SolarPACES (Solar Power and Chemical Energy Systems) Symposium, 4-7 March, Las Vegas (USA).

[7] EurObserv'ER (2013). The state of renewable energies in Europe: The 13th EurObserv'ER Report, EurObserv'ER, Paris.

[8] NREL (2014). Concentrating solar power projects, available at: www.nrel.gov (accessed 02/21).

[9] Dinter, F., Geyer, M. A. and Tamme, R. (1991). Thermal energy storage for commercial applications, Springer-Verlag, New York. 
[10] Hunold, D., Ratzesberger, R. and Tamme, R. (1992). Heat transfer mechanisms in latent-heat thermal energy storage for medium temperature applications, Proceedings of the 6th International Symposium on Solar Thermal Concentrating Technologies, Majocar, Spain, pp. 475.

[11] Pilkington (2000). Survey of thermal storage for parabolic trough power plants, NREL/SR-550-27925, National Renewable Energy Laboratory, Colorado, USA.

[12] Michels, H. and Pitz-Paal, R. (2007). Cascaded latent heat storage for parabolic trough solar power plants, Solar Energy, 81 (6), 829-837. https://doi.org/10.1016/j.solener.2006.09.008

[13] Liu, M., Tay, N. H. S., Belusko M., Bruno, F., (2015). Investigation of Cascaded Shell and Tube Latent Heat Storage Systems for Solar Tower Power Plants, Energy Procedia, 69, 913-924. https://doi.org/10.1016/j.egypro.2015.03.175

[14] Chirino H., Xu, B., Xu, X.. Parametric study of cascade latent heat thermal energy storage (CLHTES) system in Concentrated Solar Power (CSP) plants, Journal of the Energy Institute, Article in press https://doi.org/10.1016/j.joei.2018.03.007

[15] Saeed Mostafavi Tehrani, S., Shoraka, Y., Nithyanandam, K., Taylor, R. A. (2018), Cyclic performance of cascaded and multi-layered solid-PCM shell-and-tube thermal energy storage systems: A case study of the 19.9 MWe Gemasolar CSP plant, Applied Energy, 228, 240-253. https://doi.org/10.1016/j.apenergy.2018.06.084

[16] Nomura, T., Okinaka, N. and Akiyama, T. (2010). Technology of latent heat storage for high temperature $\begin{array}{llllll}\text { application: A } \quad \text { A } & \text { Inteview, } & \text { ISIJ } & \text { (9), }\end{array}$ https://doi.org/10.2355/isijinternational.50.1229

[17] Michels, H. and Hahne, E. (1996). Cascaded latent heat storage for solar thermal power stations, Proceedings of 10th International Solar Forum, Freiburg, Germany, EuroSun, Germany.

[18] Robak, C. W., Bergman, T. L. and Faghri, A. (2011). Economic evaluation of latent heat thermal energy storage using embedded thermosyphons for concentrating solar power applications, Solar Energy, 85 (10), 2461-2473. https://doi.org/10.1016/j.solener.2011.07.006

[19] Liu, M., Saman, W. and Bruno, F. (2012). Review on storage materials and thermal performance enhancement techniques for high temperature phase change thermal storage systems, Renewable and Sustainable Energy Reviews, 16 (4), 2118-2132. https://doi.org/10.1016/j.rser.2012.01.020

[20] Liu, M., Tay, N.H. S., Bell S., Belusko, M., Jacob,R., Will, G., Saman, W., Bruno, F. (2016). Review on concentrating solar power plants and new developments in high temperature thermal energy storage technologies, Renewable and Sustainable Energy Reviews, 53 (4), 1411-1432. https://doi.org/10.1016/j.rser.2015.09.026

[21] Gasia, J., Miró, L., Cabeza L. F., (2016). Materials and system requirements of high temperature thermal energy storage systems: A review. Part 2: Thermal conductivity enhancement techniques, Renewable and Sustainable Energy Reviews, 60 (7), 1584-1601. https://doi.org/10.1016/j.rser.2016.03.019

[22] Laing, D., Bauer, T., Steinmann, W. D. and Lehmann, D. (2009), Advanced temperature latent heat storage system- Design and test results, The 11th International Conference on Thermal Energy Storage, 14-17 June, Stockholm, Sweden. https://elib.dlr.de/59383/

[23] Laing, D., Eck, M., Hempel, M., Johnson, M., Steinmann, W. D., Meyer-Grünefeldt, M. and Eickhoff, M. (2012a). High temperature PCM storage for DSG solar thermal power plants tested in various operating modes of water/steam flow, Proceedings of SolarPACES Conference, 11-14 September, Marrakech, Morrocco. https://elib.dlr.de/79679/

[24] Laing, D., Bauer, T., Breidenbach, N., Hachmann, B. and Johnson, M. (2013). Development of high temperature phase-change-material storages, Applied Energy, 109, 497-504. https://doi.org/10.1016/j.apenergy.2012.11.063

[25] Steinmann, W. D., Laing, D. and Tamme, R. (2009). Development of PCM storage for process heat and power generation, Journal of Solar Energy Engineering, Transactions of the ASME, 131 (4), 04100910410094. https://doi.org/10.1115/1.3197834

[26] Tao, Y. B., and He, Y., (2018). A review of phase change material and performance enhancement method for latent heat storage system, Renewable and Sustainable Energy Reviews, 93,245-259. https://doi.org/10.1016/j.rser.2018.05.028

[27] Dhaidan N. S., Khodadadi, J.,M. (2017). Improved performance of latent heat energy storage systems utilizing high thermal conductivity fins: a review. J Renew Sustain Energy 9 (3), 034103. 
https://doi.org/10.1063/1.4989738

[28] Laing, D., Steinmann, W. D., Tamme, R. and Richter, C. (2006). Solid media thermal storage for parabolic trough power plants, Solar Energy, 80 (10), 1283-1289. https://doi.org/10.1016/j.solener.2006.06.003

[29] Laing, D., Lehmann, D. and Bahl, C. (2008). Concrete Storage for Solar Thermal Power Plants and Industrial Process Heat, 3rd International Renewable Energy Storage Conference (IRES III), 24-25 November, Berlin. https://elib.dlr.de/57976/

[30] Laing, D., Lehmann, D., Fi, M. and Bahl, C. (2009). Test results of concrete thermal energy storage for parabolic trough power plants", Journal of Solar Energy Engineering, Transactions of the ASME, 131(4), 0410071-0410076. https://doi.org/10.1115/1.3197844

[31] Laing, D., Bahl, C., Bauer, T., Fiss, M., Breidenbach, N. and Hempel, M. (2012b). High-temperature solidmedia thermal energy storage for solar thermal power plants, Proceedings of the IEEE, 100 (2), 516-524.

[32] Steinmann, W. D. and Zunft, S. (2002). TechThermo-A library for modelica applications in technical thermodymics", Otter, M. (ed.), in: 2nd International Modelica Conference, 18-19 March, Germany, The Modelica Association, pp. 217.

[33] Agyenim, F., Hewitt, N., Eames, P. and Smyth, M. (2010). A review of materials, heat transfer and phase change problem formulation for latent heat thermal energy storage systems (LHTESS)", Renewable and Sustainable Energy Reviews, 14 (2), 615-628. https://doi.org/10.1016/j.rser.2009.10.015

[34] Muhammad, M. D., Badr, O. and Yeung, H. (2014). Heat transfer in finned latent heat storage for parabolic trough solar power plants, Proceedings of IREC 2014 - 5th International Renewable Energy Congress, IEEE, Tunisia

[35] Muhammad, M. D. (2014). Development of a cascaded latent heat storage system for parabolic trough solar thermal power generation, $\mathrm{PhD}$ Thesis, Cranfield University, UK. URI: http://dspace.lib.cranfield.ac.uk/handle/1826/9303

[36] Muhammad, M. D., Badr, O. (2017). Performance of a Finned, Latent-Heat Storage System for High Temperature Applications" Applied Thermal Engineering, vol. 116, pp 799 - 810. https://doi.org/10.1016/j.applthermaleng.2017.02.006

[37] Dymola (2012). Dynamic Modelling Laboratory- User Manual, Dassaut Systemes, Sweden

[38] Solutia (2008), Therminol VP-1: Vapour Phase/Liquid Phase Heat Transfer Fluid, Technical Bulletin 7239115C, Solutia.

[39] Cao, Y. and Faghri, A. (1990). Numerical analysis of phase-change problems including natural convection, Journal of Heat Transfer, 112 (3), 812-816.

[40] Pacheco, J. E. and Gilbert, R. (1999). Overview of recent results of the Solar Two test and evaluation program", Proceedings of the 1999 ASME International Solar Energy Conference, 11-14 April, Maui, HI.

[41] Bahl, C., Laing, D., Hempel, M. and Stuckle, A. (2009). Concrete Thermal Energy Storage for Solar Thermal Power Plants and Industrial Process Heat, Proceedings of SolarPACES Symposium, 15-18 September, Berlin. Germany. https://elib.dlr.de/61290/

[42] Herrmann, U., Kelly, B. and Price, H. (2004). Two-tank molten salt storage for parabolic trough solar power plants", Energy, vol. 29, no. 5-6, pp. 883-893. https://doi.org/10.1016/S0360-5442(03)00193-2 